\title{
Erratum - La cláusula como movimiento interactivo: una perspectiva semántico-discursiva de la gramática interpersonal del español
}

A oração como movimento interativo: uma perspectiva semântico-discursiva da gramática interpessoal do

Espanhol

No artigo La cláusula como movimiento interactivo: una perspectiva semántico-discursiva de la gramática interpersonal del español publicado no periódico DELTA [online]. 2015, vol. 31, n. 1, pp. 261-301

Página $265-2^{\circ}$. Parágrafo - Onde se lia: Cada opción crea significado por cuanto comporta en sí misma valor en relación con el lugar que ocupa en el entramado de relaciones en la que se inserta, al interior y a través de distintas metafunciones, estratos y unidades.

Leia-se: Cada opción crea significado por cuanto comporta en sí misma valor respecto del lugar que ocupa en el entramado de relaciones en la que se inserta, al interior y a través de distintas metafunciones, estratos y unidades.

Página $266-1^{\circ}$. Parágrafo - Onde se lia: Es esta conceptualización del fenómeno lingüístico el que permite comprender en qué sentido, en 
la teoría de la LSF, el lenguaje es una semiótica social (Halliday 1984, 1994; Halliday y Matthiessen 2004, 2013; Martin 1992).

Leia-se: Es esta conceptualización del fenómeno lingüístico el que permite comprender en qué sentido, en la LSF, el lenguaje es una semiótica social (Halliday 1984, 1994; Halliday y Matthiessen 2004, 2013; Martin 1992).

Página 267 - nota 2 - Onde se lia: 2. Véase Anexo 1 para convenciones sistémico-funcionales empleadas a lo largo de este artículo (cf. Matthiessen \& Halliday 2009: 98, Halliday y Matthiessen 2013: ix)

Leia-se: 2. Véase Anexo para convenciones sistémico-funcionales empleadas a lo largo de este artículo (cf. Matthiessen \& Halliday 2009: 98, Halliday y Matthiessen 2013: ix)

Página $268-1^{\circ}$. Parágrafo - Onde se lia: El sistema de MERCANCÍA, por su parte, dice relación con aquello que se intercambia, a saber, bienes y servicios no lingüísticos - si el hablante requiere $u$ ofrece un curso de acción no codificado lingüísticamente - o información - si el hablante pide o da información que es necesariamente codificada lingüísticamente.

Leia-se: El sistema de MERCANCÍA, por su parte, dice relación con aquello que se intercambia, a saber, bienes y servicios no lingüísticos - si el hablante requiere u ofrece un curso de acción no codificado lingüísticamente - o información - si el hablante pide o da información que es necesariamente codificada en forma lingüística.

Página 270 - último parágrafo - Onde se lia: = Ahora bien, la LSF supone que las funciones de habla básicas están presentes en todas las lenguas: en todas ellas los hablantes negocian roles y mercancías semióticas.

Leia-se: El marco descriptivo de la LSF supone que las funciones de habla básicas están presentes en todas las lenguas: en todas ellas los hablantes negocian roles y mercancías semióticas. 
Página $272=2^{\circ}$. Parágrafo - Onde se lia: Todo elemento que no corresponda a este núcleo, es analizado dentro del Residuo (Figura 6):

Leia-se: Todo elemento que no corresponda a este núcleo, es analizado dentro del Residuo como se muestra en la Figura 6:

Página $277-1^{\circ}$. Parágrafo - Onde se lia: De este modo, la autora demuestra que si bien la gramaticalización de funciones de habla básicas en un sistema de modo tiende a aplicarse a distintas lenguas, las diferencias fundamentales residen en los recursos y configuraciones estructurales que motivan el establecimiento de las opciones sistémicas en una lengua y otra (1995: 2, 23).

Leia-se: De este modo, la autora plantea que, si bien la gramaticalización de funciones de habla básicas en un sistema de modo tiende a aplicarse a distintas lenguas, las diferencias fundamentales residen en los recursos y configuraciones estructurales que motivan el establecimiento de las opciones sistémicas en una lengua y otra (1995: 2, 23).

Página 278 = último parágrafo - Onde se lia: No obstante, estas propuestas coinciden en el papel fundamental que desempeña el grupo verbal como un todo en distinciones interpersonales básicas de estas lenguas.

Leia-se: No obstante, estos trabajos coinciden en el papel fundamental que desempeña el grupo verbal como un todo en distinciones interpersonales básicas de estas lenguas.

Página $279-1^{\circ}$. Parágrafo - Onde se lia: Las propuestas que en el marco de la LSF contribuyen a caracterizar la gramática interpersonal desde una perspectiva semántico-discursiva serán el punto de partida para el análisis que se propondrá a continuación para la cláusula española.

Leia-se: Las propuestas que en el marco de la LSF contribuyen a caracterizar la gramática interpersonal desde una perspectiva semántico-discursiva serán el punto de partida en el análisis que se propondrá a continuación para la cláusula española. 
Página $279=2^{\circ}$. Parágrafo - Onde se lia: Cabe establecer ahora cuáles son las especificidades del español cuando la cláusula es examinada desde las perspectivas semántico-discursivas revisadas en los apartados ya revisados.

Leia-se: Cabe establecer ahora cuáles son las especificidades del español cuando la cláusula es examinada desde las perspectivas semántico-discursivas revisadas en los apartados anteriores.

Página $279-3^{\circ}$. Parágrafo - Onde se lia: En forma preliminar, solo se presenta un análisis de constituyentes del rango de grupo/frase, sin especificar aún las funciones estructurales interpersonales que realiza cada uno de ellos en el rango de la cláusula (véanse convenciones para las glosas en el Anexo):

Leia-se: En forma preliminar, solo aparece un análisis de los constituyentes del rango de grupo/frase, sin especificar aún las funciones estructurales interpersonales que realiza cada uno de ellos en el rango de la cláusula (véanse convenciones para las glosas en el Anexo):

Página $283=1^{\circ}$. Parágrafo - Onde se lia: Ahora bien, los recursos básicos centrados en el grupo verbal finito también desempeñan un papel significativo en la realización congruente de las distintas funciones de habla en español, como puede verse en los siguientes extractos tomados de encuentros telefónicos de servicio (de los datos estudiados por Castro 2010).

Leia-se: Los recursos básicos centrados en el grupo verbal finito también desempeñan un papel significativo en la realización congruente de las distintas funciones de habla en español, como puede verse en los siguientes extractos tomados de encuentros telefónicos de servicio (de los datos estudiados por Castro 2010).

Página $284=2^{\circ}$. Parágrafo - Onde se lia: Las cláusulas interrogativas polares constituyen el recurso típico para los movimientos de pregunta que buscan confirmación, mientras que las interrogativas 
elementales se asocian de manera regular a movimientos de pregunta que buscan información (cf. Caffarel 1995: 7).

Leia-se: Las cláusulas interrogativas polares constituyen el recurso típico para los movimientos de pregunta que incitan a una confirmación, mientras que las interrogativas elementales se asocian de manera regular a movimientos de pregunta que buscan elicitar información (cf. Caffarel 1995: 7).

Página $285=2^{\circ}$. Parágrafo - Onde se lia: En el ejemplo presentado a continuación, el interlocutor entrega por teléfono una serie de instrucciones a alguien (cuyas réplicas no pueden ser oídas):

Leia-se: En el ejemplo presentado a continuación, el hablante entrega por teléfono una serie de instrucciones a otra persona (cuyas réplicas no pueden ser oídas):

Página $288=1^{\circ}$. Parágrafo - Onde se lia: Esta interpretación del núcleo interpersonal del español, como puede observarse, difiere del francés (Caffarel 1995, 2006), pero también del portugués (Figueredo 2011, Gouveia 2010) en cuanto a que no se incluyen las funciones de Sujeto y Finito al interior del Negociador.

Leia-se: Esta interpretación del núcleo interpersonal del español, como puede observarse, difiere del francés (Caffarel 1995, 2006), pero también del portugués (Figueredo 2011, Gouveia 2010) en cuanto a que no se incluyen las funciones de Sujeto y Finito dentro del Negociador.

Página $288=2^{\circ}$. Parágrafo - Onde se lia: En cuanto a otros contrastes interpersonales claves asociados a la negociabilidad de las proposiciones y propuestas, su vinculación con un elemento Finito discreto no parece encontrar justificación en el rango de la cláusula española. 
Leia-se: En cuanto a otras distinciones interpersonales claves asociadas a la negociabilidad de las proposiciones y propuestas, su vinculación con un elemento Finito discreto no parece encontrar justificación en el rango de la cláusula española.

Página $296-1^{\circ}$. Parágrafo - Onde se lia: Este constituyente se erige, de este modo, como un recurso fundamental tanto en español como en otras lenguas románicas.

Leia-se: Este constituyente se presenta, de este modo, como un recurso fundamental tanto en español como en otras lenguas románicas.

Página 297 - "Referencias bibliográficas" - Onde se lia: QuIROz, Beatriz. 2008.

Leia-se: Quiroz Olivares, Beatriz. 2008.

Página 300 - Onde se lia: Anexo 1 Convenciones empleadas en este artículo

Leia-se: Anexo - Convenciones empleadas en este artículo 